\title{
Measuring Potential Output
}

\author{
Amy Y. Guisinger, Assistant Professor, Lafayette College \\ Michael T. Owyang, Assistant Vice President and Economist \\ Hannah G. Shell, Senior Research Associate
}

There are several ways to measure potential economic output. Do different measures lead to different central bank policy decisions? How about data revisions? As it turns out, different measurements of potential output yield only slightly different conclusions about the output gap. Policy is likely to have unfolded just as it did regardless of the measurement choice.

A s the central bank of the United States, the Federal Reserve operates under a dual mandate to stabilize long-term inflation and maintain maximum sustainable employment. The Federal Reserve achieves these goals through monetary policy tools aimed at stabilizing both unemployment and inflation throughout the various stages of the business cycle. This action is referred to as stabilization policy.

So many ways to measure potential output, so little consensus...

But different measurements don't necessarily alter central bank policy decisions.

One of the goals of stabilization policy is to reduce the output gap-the difference between potential and actual output during downturns. Potential output, however, is an unobserved variable whose definition can vary. In fact, decades of academic research have failed to converge on a single measure of potential output. For example, some view potential output as the level of output that can be produced when employment is at its maximum sustainable level. Others use trend measures of output to measure potential. In a recently published Review Early Edition article, Guisinger, Owyang, and Shell (2018) survey some of these measures, constructing potential output series using both current time series data (all of the data available through June 2017) and real-time data (the actual data that would have been available at different points in the sample). Real-time data are important for this type of comparison because most economic variables are heavily revised, and using real-time data allows the authors to see whether dif-

\section{The Policy Rate Prescribed by a Standard Interest Rate Rule Calculated Using Six Measures of Potential Output}

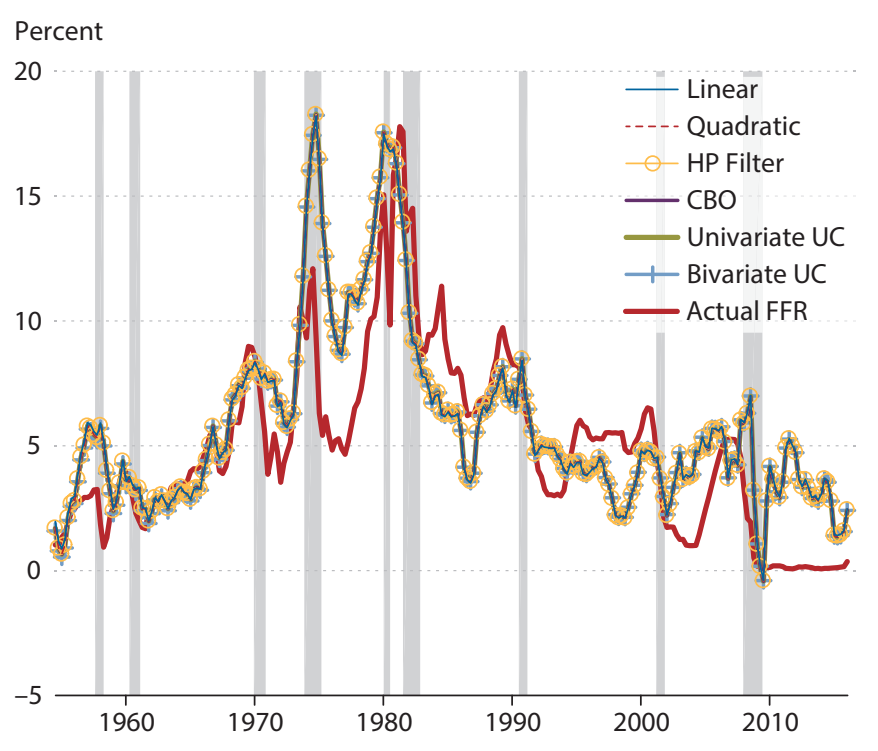

NOTE: Gray bars indicate recessions as determined by the National Bureau of Economic Research. FFR, Federal funds rate. HP, Hodrick Prescott. UC, Unobserved component. See Guisinger, Owyang, and Shell (2018) for details on the six measures. SOURCE: Guisinger, Owyang, and Shell (2018); FRED ${ }^{\circledR}$; Bureau of Economic Analysis; CBO; Bureau of Labor Statistics; Board of Governors of the Federal Reserve System; and authors' calculations.

ferent measurement methods would have led to different policy decisions given the information known then.

The authors construct six different measures of potential output: a linear trend, a quadratic trend, the Congressional Budget Office (CBO) measure, and three filtered trends. They then compare these measures across methods and across time. They also use the measures to compute the monetary policy prescription in a standard interest rate rule (see figure) and find very little difference across methods. Ultimately, the authors find that even though different 


\section{ECONOMIC Synopses}

measures of potential output yield different output gaps, the differences between these measures have little impact on policy prescriptions, meaning central bank stabilization policy is likely robust to changes in estimation methodology for potential output.

\section{Reference}

Guisinger, Amy Y.; Owyang, Michael T. and Shell, Hannah G. "Comparing Measures of Potential Output." Federal Reserve Bank of St. Louis Review Early Edition, August 2018; https://research.stlouisfed.org/publications/ review/2018/08/13/comparing-measures-of-potential-output. 